\title{
Using Social Media to Improve Undergraduate Students' Mental Health
}

\author{
Thapanee Seechaliao and Chanita Rungrueng
}

\begin{abstract}
This paper describes the use of social media to improve undergraduate students' mental health. The research method included in-depth interview and a focus group approach. Twenty-four undergraduate students of the education faculty in Mahasarakham University participated in this study. Sixteen in-depth interviews and a focus group of eight students were conducted. Data were collected and analyzed by content analysis technique. The results showed that participants faced many mental health problems but rarely used professional mental health services at the counseling center. They deemed that social media was one of the best communication channels to reduce their problems. They could learn how to solve problems, apply and try to solve their problems by themselves based on what they learned in social media. Most students suggested that Thai government or related organizations should provide more communication channels such as social media to contact or consult with clinical psychologists. These results suggested that developing multiple communication channels in a counseling center might be needed.
\end{abstract}

Index Terms-Social media, mental health, undergraduate students, adolescents.

\section{INTRODUCTION}

Most global people were suffered from mental illness (Sarris, Glick, Helgason, Veizer, \& Lake, 2014) [1]. Thai people also has many mental health problems related with increasing social issues [2] (Lortrakul et al., 2012). Common mental health problems include stress, anxiety, and depression. Environments usually influence the mental health of a person (Yurayart, 2012) [3]. To help improve mental health, Thai government provides mental health services in nationwide hospitals and 18 psychiatric hospitals (Department of Mental Health, Thailand, 2013 [4]). Mental health services involve the prevention and psychological treatments or psychological interventions such as counseling, psychological assessment, psychotherapy, and behavior modification. These services are helpful in improving patients' behaviors and relieving their distress [2] (Lortrakul et al., 2012).

Undergraduate students are adolescents whom are of suitable age for prevention of mental health disorders [5] (Buckelew, Yu, Brindis, \& English, 2008). Many mental

Manuscript received January 8, 2016; revised March 23, 2016. This work was supported in part by Faculty of Education, Mahasarakham University, Thailand for the International Conference Grant.

The authors are with the Department of Educational Technology and Communications, Faculty of Education, Mahasarakham University, Nakhonsawan Road, Muang District, Mahasarakham, 44000 Thailand (e-mail: thapanee.see@ hotmail.com, chanita.rng@gmail.com). health disorders such as mood disorders, impulse-control disorders, anxiety disorders, substance abuse problems, and eating disorders often begin in adolescence [5] (Buckelew et al., 2008). The World Health Organization (WHO) is also interested in these problems, in 2005 WHO called for national action in the field of child and adolescent mental health services [6] (Fann, Bombardier, Richards, Tate, Wilson, \& Temkin, 2011).

Department of Educational Psychology and Guidance, Faculty of Education, Mahasarakham University provides the counseling center pertaining mental health problems for lecturers, students, staffs and others. Clinical psychologists help them to understand themselves through psychological assessments. If they have any psychological problems, psychological treatments are provided. Early detection and intervention can help them prevent or reduce more psychological problems. However, only a few undergraduate students use the mental health services provided by the counseling center; the most others such as faculty members rarely use them.

Online social media can be used in informal mental health care for three purposes: (1) individuals have experience of mental disorder may share information and develop understanding, (2) social and emotional support, and (3) it can serve as a means of feedback to mental health service providers [7] (Shepherd, Sanders, Doyle, \& Shaw, 2015). Shepherd et al's (2015) [7] study identified that much online discussion was related to care experience and practical means of addressing the concerns raised, and these online discussion and statements were focused more on individual experience in mental disorder in nature.

Given the potential for social media to reduce the mental health problems, this research study aims to describe about using social media to reduce the mental health problems by in-depth interview and a focus group approach. The study results could serve as valuable and fundamental sources to develop communication channels in the counseling center of Faculty of Education in Mahasarakham University.

\section{LITERATURE REVIEW}

The literature review about using social media to improve undergraduate students' mental health is pretended as follows:

\section{A. Social Media in Higher Education}

The majority of lecturers in higher education believe that social media sites offer great value in teaching, such as online 
video, podcasts, and wikis (Moran, Seaman, \& Tinti-Kane, 2011) [8]. Additionally, the benefits of social media include supporting lecturers' professional careers and promoting collaborative learning (Moran et al., 2011) [8], as well as facilitating learning activities at university [9] (Irwin, Ball, Desbrow, \& Leveritt, 2012).

Facebook is currently considered the most popular platform for online social networking among college students For example, Facebook was used for four university's courses to provide information relevant to the courses and expand opportunities for student interaction [9] (Irwin et al, 2012). Nowadays, students have been adopted Facebook widely [10] (Roblyer, McDaniel, Webb, Herman, \& Witty, 2010), because it has a potential to becomes a valuable resource to support their educational communications and collaborations with lecturers [9] (Irwin et al., 2012).

In Thailand, lecturers' attitude towards social media integration in higher education was studied. They agreed that social media was easy to conduct in online courses (Seechaliao, 2015) [11]. Seechaliao's (2015) [11] research indicated that the characteristics of social media can be an effective communication channel between lecturers and learners, and these characteristics can be used as a supportive means to create a learning community of learners between classes and universities. Given that social media is a great communication tool, it can also be used to facilitate communication and conversations between mental health providers and receivers.

\section{B. Using Social Media to Improve Undergraduate Students' Mental Health}

Undergraduate students usually face with many mental health disorders including mood disorders, impulse-control disorders, anxiety disorders, substance abuse problems, and eating disorders, which often begin in adolescence [5] (Buckelew et al., 2008). To reduce mental health problems and support mental health needs, Department of Educational Psychology and Guidance in Faculty of Education at Mahasarakham University provides mental health services in the counseling center for lecturers, students, staffs and others.

Strickland (2014) [12] explored the relationship between social media use and mental health in the young adult population. This research suggests that practitioners must understand that social media could be a potential cause or outcome of mental health problems. Strickland (2014) [12] emphasized that mental health practitioners and health care providers could provide young adults with proper recommendations and guidance associated with the risks of using social media if they are aware of the importance and potential threats to young adults' mental well-beings from social media.

\section{ReSEARCH Methodology}

The research methodology was in-depth interview and a focus group approach, as follows:

\section{A. Objective}

The purpose of this study was to use social media to improve undergraduate students' mental health.

\section{B. Participants}

The participants were twenty-four undergraduate students of education faculty in Mahasarakham University who were from Department of Curriculum and Instruction, Department of Educational Psychology and Guidance, Department of Sport Science, and Department of Educational Technology and Communications. Sixteen students were selected for in-depth interview and eight students were selected for the focus group.

\section{Data Analysis}

The data were collected by in-depth interview and the focus group approach and were analyzed by the content analysis technique.

\section{FINDINGS}

Most undergraduate students rarely used professional mental health services

Undergraduate students often face many mental health problems such as stress, anxiety, and depression. Department of Educational Psychology and Guidance in Faculty of Education at Mahasarakham University provides mental health services in the counseling center to lecturers, students, staffs and those who need such services. The findings revealed that many undergraduate students tried to solve their mental health problems by consulting close friends or parents but rarely come to the mental health services. Most undergraduate students worried that others may look at them as a psychotic patient, and that resulted in them always refusing mental health services or avoiding to disclose their identities.

Social media provided relevant information and social support for undergraduate students

Undergraduate students indicated that they considered social media one of the best ways to reduce their mental health problems. Whenever undergraduate students had problems concerning relationships, family issues, or academic problems, they often used social media to seek for help with their problems. For example, they could have a conversation with their close friend via facebook chat to reduce stress and get relieved. They searched information related to their mental health problems through relevant websites or blogs. Through these searches, they found that others who had similar mental health issues used different ways to solve problems. Moreover, they also discussed and shared some programs or apps in social network that can be used either as a communication means or to help obtain useful resources and information. For example, some mentioned that a social network program called "ask.fm" which allowed anonymous questions. The information they found in social media helped them understand their own mental issues and gain social support, in which they learned and applied some ways to solve their own problems. 
More communication channels for acquiring mental health information were recommended

The findings revealed that most undergraduate students suggested that Thai government or related organizations should provide more communication channels to contact or consult with clinical psychologists. Social media was one of the best ways to reduce their mental health problems because it was easy to use for communication with others and could serve as effective, supportive tools to create a mental health problem-solving community for learners, psychotic patients, consultants, and others who are related to this field or issue.

\section{DISCUSSION}

The results of this research showed that undergraduate students rarely utilize mental health services, although the counseling center in Mahasarakham University has been provided relevant mental health services for lecturers, students, staffs and others. Many students believed that they could resolve their mental health problems by using social media. These results corresponded well with Mackenzie, Pagura, and Sareen's (2010) [13] statement that "a lack of perceived need for mental health services and self-sufficiency beliefs are significant barriers to use mental health services." However, mental health can be improved and enhanced by increasing one's health knowledge and behaviors [14] (Hanandita \& Tampubolon, 2014). It seems that students considered social media a useful tool to acquire mental health related resources and information. Therefore, social media can be used to improve and increase mental health, if more accurate information and reliable resources are provided in social media.

Undergraduate students deem that social media was one of the best ways to reduce their mental health problems. Hence, they often used social media, such as facebook, websites, or blogs, to gain relevant information and tried to use the information acquired from social media to resolve their own mental health problems, without going to professional mental health services. These results are similar to some studies indicated that individuals who first seek help from religion or spiritual advisors are less likely to utilize professional mental health services (e.g., John \& Williams, 2013 [15]).

Most undergraduate students suggested that more communication channels and platforms should be provided in order to contact or consult with clinical psychologists or professional practitioners. These results suggested that developing multiple communication channels in a counseling center might be needed, especially for the counseling center in Mahasarakham University. For young adults, such as undergraduate students, using social media is very easy. In addition, social media is one of the most important means of communication. Moreover, the characteristics of social media can be used as a supportive means to create a learning community of learners between classes and universities (Seechaliao, 2015) [11]. Therefore, making good use of social media to create a mental health problem-solving community for psychotic patients, consultants, and professional practitioners and others who are in the related fields and to provide accurate and reliable resources and information could provide a substantial improvement for mental health.

\section{ACKNOWLEDGMENTS}

We would like to express our sincere thanks to Faculty of Education, Mahasarakham University, Thailand for the International Conference Grant. We would also like to thank Bi-Jen Hsieh for her suggestions and feedback on this paper.

\section{REFERENCES}

[1] J. Sarris, R. Glick, C. Helgason, C. Veizer, and J. Lake, "The international network of integrative mental health (INIMH)," Advances in Integrative Medicine, vol. 1, pp. 59-60, 2014.

[2] M. Lortrakul et al., Textbook of Ramathibodi Psychiatry, Bangkok: Beyond Enterprise, 2012.

[3] P. Yurayart, "Mental health and adjustment in modern society," Psychology in Modern Life Style, Mahasarakham University Press, 2012.

[4] Department of Mental Health. (2013). Hospitals under the Department of Mental Health. [Online]. Available: http://www.dmh.go.th/links/links.asp?catid=18

[5] S. Buckelew, J. Yu, C. D. Brindis, and A. English, "Innovations in preventive mental health care services for adolescents," Journal of Adolescent Health, vol. 42, no. 5, pp. 519-525, 2008.

[6] J. R. Fann, C. H. Bombardier, J. S. Richards, D. G. Tate, C. S. Wilson, and N. Temkin, "Depression after spinal cord injury: Comorbidities, mental health service use, and adequacy of treatment," Archives of Physical Medicine and Rehabilitation, vol. 92, no. 3, pp. 352-360, 2011.

[7] A. Shepherd, C. Sanders, M. Doyle, and J. Shaw, "Using social media for support and feedback by mental health service users: thematic analysis of a twitter conversation," BMC Psychiatry, vol. 15, p. 29 2015 .

[8] M. Moran, J. Seaman, and H. Tinti-Kane, Teaching, Learning, and Sharing: How Today's Higher Education Faculty Use Social Media, Boston, MA: Pearson Learning Solutions, 2011.

[9] C. Irwin, L. Ball, B. Desbrow, and M. Leveritt, "Students' perceptions of using Facebook as an interactivelearning resource at university," Australasian Journal of Educational Technology, vol. 28, no. 7, pp 1221-1232, 2012.

[10] M. D. Roblyer, M. McDaniel, M. Webb, J. Herman, and J. V. Witty, "Findings on Facebook in higher education: A comparison of college faculty and student uses and perceptions of social networking sites," The Internet and Higher Education, vol. 13, no. 3, pp. 134-140, 2010.

[11] T. Seechaliao, "Lecturers' attitude towards the social media integration in courses: A case study in Thailand," in D. Slykhuis and G. Marks, Eds. in Proc. Society for Information Technology \& Teacher Education International Conference 2015, Chesapeake, VA: Association for the Advancement of Computing in Education (AACE), pp. 1039-1044, 2015.

[12] A. C. Strickland, "Exploring the effects of social media use on the mental health of young adults," Thesis, Florida: University of Central Florida, 2014

[13] C. S. Mackenzie, J. Pagura, and J. Sareen, "Correlates of perceived need for and use of mental health services by older adults in the collaborative psychiatric epidemiology surveys," The American Journal of Geriatric Psychiatry: Official Journal of the American Association for Geriatric Psychiatry, vol. 18, no. 12, pp. 1103-1115, 2010.

[14] W. Hanandita and G. Tampubolon, "Does poverty reduce mental health? An instrumental variable analysis," Social Science and Medicine, vol. 113, pp. 59-67, 2014.

[15] D. A. John and D. R.Williams, "Mental health service use from a religious or spiritual advisor among Asian Americans," Asian Journal of Psychiatry, vol. 6, no. 6, 2013.

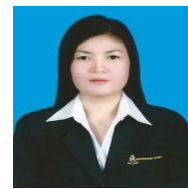

Thapanee Seechaliao received a Ph.D. in 2010 from Chulalongkorn University, Thailand, and a scholarship from the Commission on Higher Education, Thailand under the grant program Strategic Scholarships for Frontier Research Network for the Ph.D. Program Thai 
doctoral degree. She received the Best Paper Award from the 2012 International Conference on Education and Management Innovation, Singapore and the Dissertation Award 2013 from the National Research Council of Thailand (NRCT). Dr. Seechaliao is currently a lecturer in the Educational Technology and Communications Department, Faculty of Education, Mahasarakham University, Thailand. Her fields of research include educational technology, instructional design, and diffusion of innovations.

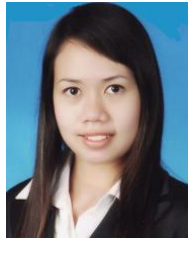

Chanita Rungrueng received her M.S. in clinical psychology at Mahidol University, Thailand in 2009. She have been a lecturer in Autistic Research Center, Faculty of Education, Khonkhan University, Thailand. Now she is a lecturer in Department of Educational Psychology and Guidance, Faculty of Education, Mahasarakham University, Thailand. Her fields of research is psychological testing. 